\title{
ATATÜRKÇÜLÜK'TE HOŞGÖRÜ
}

\author{
Dr. Issmet GÖRGÜL
}

\section{GİRIŞ̧}

1995 yıll, dünyada "Hoşgörü Yllı" ilan edildi. Evrensel değerleri anlama ve yerleştirme açısından önemli adımdır. Ancak hoşgörü kavramını algılamadaki, özellikle uygulamadaki farklılıklar, iyi niyetle atılmıs bu adımı sadece sözde bırakmaktadır. Görülen odur ki, hoşgörünün evrensel bir değer olarak yerleşmesi için daha çok zaman geçecektir.

Evrensel değer denilenler, ulusal değerler arasında yer almadıkça evrenselleşemez. Bu nedenle "hoşgörü" öncelikle ulusal değer olarak alg1lanmalıdır. Evrensel değer yönü ise şimdilik konumuz dışıdır.

Hoşgörü, Türk'ün tarihi bir niteliği olarak kabul edilir. İmparatorluklar kurabilmesi ve uzun süre yaşatabilmesi de buna bağlanır. Doğrudur. Ancak bu nitelik, süreklilik göstermemiş, zaman zaman kesintiye uğramıştır. Kesintiye uğradığı dönemlerde ise dini taassubun, cehaletin ve bazen de ırki taassubun ağırlık kazandığı görülmektedir. Sonucunda da siyasi değişiklikler meydana gelmiş, genelde devlet parçalanmıştır.

Bugün de dini taassubun ağırlık kazanmaya başladığı, cehaletten kaynaklanan taassubun arttığı ve irki taassubun körüklendiği görülmektedir. Tarihi tekerrür ettirmemek için bu kavram üzerinde önemli durulmalidir.

Hoşgörü kelimesi kişi seviyesinde sık kullanılır. Zora düşüldüğünde, bir hata yapıldığında, ilgiliden veya büyükten bu kelimeyi hatrlaması beklenilir. Affettiğinde hoşgörülü, kuralları uyguladığında ise hoşgörüsüz denilir ve genelde hoşgörü, kişi seviyesinde bu dar çerçevede algılanır. Acaba hoşgörü, gerçekten bu kadar mıdır, başka boyutlan yok mudur? Kişi seviyesinde nasıldır; toplum, devlet seviyesinde nasıldır? Atatürkçülük'te bu nasıl anlaşılmalı, uygulanmalıdır? Bu soruların yanıtları için önce hoşgörünün anlamı üzerinde duralım. İșe de sözlük ve ansiklopedilerden başliyalım. 


\section{HOŞGÖR $\ddot{U}$ 'NÜN ANLAMI}

Hoşgörü, Türk Dil Kurumu sözlüğünde müsamaha, tolerans kelimeleriyle eşanlamlı gösterilmekte; görmezlikten gelme, göz yumma anlamları ile açıklanmaktadır. Türkçe sözlüğümüz hdşgörüyü sadece bir kelime olarak ele alyyor ve kavram ynüne yer vermiyor.

Meydan Larousse ansiklopedisi de hoşgörüyü müsamaha ve tolerens kelimeleriyle eş anlamlı olarak ele alır ve bir kavram olarak şöyle açıklar:

"Savundukları görüsler ve açı̆̆a vurdukları duygular bizimkilerle çelişen kimseleri saburla karşllama, hos görme."

Osmanlıca-Türkçe sözlüklerde müsamaha için şu açıklama yapılır:

Görmezliğe gelme, göz yumma; dikkat, aldırıs etmeme".

Enoyolopedia Britannica Ansiklopedisi toleransı şöyle açıklar:

"Müsamaha etmek, tahammül etmek"

"Başa insanların hareket ve hükümlerinde serbest olmalarına müsaade edilmesi; cemiyetin gidiş ve görüşlerine aykır olan fikirlere karşı sabırla ve peşin hükümsüz tahammül ve müs amaha gösterilmesi".

Hoşgörü kelimesi eski dilde, mümahanın yanı sıra tesamuh ve hamuliyet kelimeleri ile de ifade ediliyor.

Tesamuh hoşgörü, dikkatsiz, kayıtsız davranma anlamında; hamuliyet ise dayanma, sabırlılık, hoşgörü, tolerans anlamında kullanılıyor.

Hoşgörünün eski dildeki zıt anlamlısı taassuptur. Taassup ise sözlükte şöyle açıklanır:

"Birine taraflı olma; din işlerinde aşırı taraflılık edip başka dinde, inançta olanlara düşman oluş".

Taassubun yaşayan Türkçe' deki karşllığı bağnazlıktır. Bağnaz; "Bir düşünceye, bir inanışa aşırı ölçüde bağlanıp ondan başka düşünce ve inanışa karşı olan, onu kabul etmeyen, mutaassip" anlamında kullanılır.

Bağnazın eş anlamlısı ise fanatikdir. "Bir kimseye veya bir şeye aşarı düşü̈nlük ve tutkuyla bağlı olma" anlamını ifade eder. lir:

Hoşgörü ile ilgili kelimelerin birbirleriyle ilişkileri şöyle özetlenebi- 
Hoşgörü taassupsuzluk, müsamaha, tolerans, tahammül.

Hoşgörü hoşgörüsüzlük, taassup, bağnazlık, fanatiklik.

Hoşgörülü hoşgörüsüz, mutassıp, bağnaz, fanatik.

Görüldüğü gibi hoşgörü; duygu, düşünce, inanç, vicdan, tavır ve hareketlerle ilgili bir kavram olarak karşımıza çıkıyor. Ancak kaynaklar, hoşgörüye eş anlamlı olarak kullandıkları kelimenin durumuna göre birbirinden farklı anlam veriyorlar. Örneğin hoşgörünün zıt anlamlısı taassubu, sadece dine, inanca yönelik olarak açıklıyorlar. Başka bir kaynak ise hoşgörüyü sadece görüş ve duygu yönünden ele alyyor.

Bunlar tek tek doğrudur ama noksandır. Hoşgörü bir kavramdır. Atatürkçülüğün ana kavramlarından biridir. Sosyal hayatın en faydalı ve şartı olan bir erdemdir. insanlığın devamı için zorunlu olan, gerek kişi gerekse toplum olarak huzur içinde yaşamanın, vatan ve millet bütünlüğünün devamını sağlamanın bir anahtarıdır. Demokrasinin şartıdır. Laikliğin şartıdır. Milliyetçiliğin şartıdır. Căğdaşlaşmanın şartıdır. Bu nedenle bu önemli kavram dar çerçevede ele alınmamalıdır. Bütün yönleri ile ele alınmalıdır ki anlaşılsın, uygulansın.

Atatürkçülük'te hoşgörü sözlük ve ansiklopedilerde ifade edilen duygu, düşünce, inanç kavramlarının tamamını kapsar ve bunlara davranı̧̧ da ilave eder.

Atatürkçülük'te hoşgörü şöyle anlaş1lır ve anlaşılmalıdır.

Hoşgörü; herkesin duygu, düşünce, inanç ve davranışlanında serbest olmasına izin vermek; kișilerin duygu, düsünce, inanç ve davranışlanındaki aykırılıklara, zıtlıklara ön yargısız katlanmak ve görmezlikten gelmektir.

Atatürkçülükte hoşgörünün iki boyutu vardır. Biri tanımdaki serbest olmaya izin vermek açısından devlete yöneliktir. Diğeri ön yargısız katlanma ve göz yumma açısından kişilere, topluma yöneliktir.

Devletimiz, anayasa ile hoşgörüyü bir ilke olarak benimsendiğini ortaya koymuş ve bunun sağlanmasını da devlet olarak üstlenmiştir. Anayasa, kişinin hakları ve ödevleri başlığı altında hoşgörüyü kapsamına alır ve bazı maddelerde şu ifadelere yer verir.

"Madde 17: Herkes, yașama, maddi ve manevi varlığını koruma ve gelişstirme hakkına sahiptir." Bu maddeyle devlet, kişinin varlığını geliştirmesi için düşünce ve davranışına izin veriyor ve bunu bir hak olarak teslim ediyor.

"Madde 24: Herkes, dini inanç ve kanaat hürriyetine sahiptir... Kimse, ibadete, dini ayin ve törenlere katılmaya, dini inanç ve kanaatlerini açıklamaya zorlanamaz; dini inanç ve kanaatlerinden dolayı kınana- 
maz ve suçlanamaz." Bu maddeyle de kişi vicdanının serbestliğini kabul ediyor ve bu serbestliği koruma altına alıyor.

"MADDE 25: Herkes düsünce ve kanaat hürriyetine sahiptir. Kimse... Düşünce ve kanaatleri sebebiyle kınanamaz ve suçlanamaz"

Bu maddeyle ise düşünce serbestliğine izin veriyor.

"Madde 26: Herkes düsünce ve kanaatlerini söz, yazı, resim veya başka yollarla tek başına veya toplu olarak açıklama ve yayma hakkına sahiptir."

"Madde 27: Herkes bilim ve sanatı serbestçe öğrenme ve ögretme, açıllama, yayma ve bu alanlarda her türlü araştırma hakkına sahiptir." Bu maddelerle de kişinin beyni, dili, kalemi ve eliyle ürettiklerini yayma serbestisine izin veriyor.

Anayasa, belli başlılarını aldığımızı bu maddelerle hoşgörüyü, hoşgörünün esasi olan duygu, düşünce, inanç ve davranışlarda sebrbestiyi, devlet ve toplum düzeninin vazgeçilmez bir unsuru olarak ortaya koyuyor ve bunların korunmasını da temel hak ve hürriyetlerin korunması başlığı altında güvenceye alıyor. Yani bu müsaadeleri hem veriyor, hem de bunların gerçekleşmesini, bu maddelerin işlemesini devlet güvencesi altına alıyor.

Atatürkçülükte hoşgörünün devlete yönelik bölümünü böyle açıkladıktan sonra şimdi kişiye, topluma yönelik bölümüne bakalım.

Hoşgörünün tanımında, kişi ve topluma yönelik bölümü "Kişilerin, duygu, düsünce, inanç ve davranışlardaki aykırılıklara, zıtlıklara önyargısız katlanmak ve görmezlikten gelmek" diye ifade etmiştik.

Dikkat edilirse buradaki, duygu, düşünce, inanç ve davranışlar, anayasamızda serbestliğine izin verilen ve devlet tarafından korunan hususlardır. O halde Atatürkçülük'te hoşgörünün kişiye, topluma yönelik bölümü için şunu diyebiliriz. Devletin izin verdiği bir hususu, bir kişinin veya bazı kişilerin kısıtlaması veya yasaklaması olamaz; devletin güvence altına aldığ ması da olamaz. Devletin serbestliğine müsaade ettiği hususlara herkes eşit şartlarda uymaya zorunludur. Aksi davranış suç olduğu gibi insanlık dışıdır. Benim gibi düşünmüyor, benim inandığıma inanmıyor, benim dinimi benimsemiyor diye dövmek, öldürmek, yakmak ise vahşiliktir, çağdışılıktır. 
Atatürkçülük ve Atatürkçü bunları asla hoşgörüyle karşılamaz; Atatürkçülük bu çağdışı zihniyeti yok etmek için vardır, topluma hoşgörüyü yerleştirmek için vardır. lim.

Şimdi Atatürk'ün Hoşgörü-Taassupsuzluk üzerine yazdıklarını göre-

\section{ATATÜRK'ÜN TAASSUPSUZLUK (TOLERANS) ÜZERINNE YAZDIKLARI}

Atatürk, bugünkü yurttaşlık bilgisi dersinin karşılığı olan "Vatandaş İçin Medeni Bilgiler" isimli ders kitabına düzeltme ve ilavelerinin dışında el yazısı ile 200 sayfalık katkıda bulunmuş, yani büyük bölümünü bizzat yazmıştır. İşte bu ders kitabının vicdan hürriyeti konusunda taassupsuzluk başlığı altında, hoşgörüyü işlemiştir. Vicdan hürriyetine şöyle giriş yapılmıştır:

"Vicdan hürriyeti, her fert, istediğini düşünmek, istediğine inanmak, kendine mahsus siyasi bir fikre sahip olmak, mensup olduğu bir dinin icapların yapmak veya yapmamak hak ve hürriyetine sahiptir. Kimsenin fikrine ve vicdanina hakim olunamaz."

"Vicdan hürriyeti mutlak ve taarruz edilmez, ferdin tabii haklarinın en mühimlerinden taninmalıdır."

Bu girişin arkasından Atatürk'ün taassupsuzluk konusundaki açıklamaları yer alır. Öneminden ve 1930 'da yazılmasına rağmen bugünü yansıtmasından dolayı açıklamanın tamamını almayı faydalı buluyorum.

\section{TAASSUPSUZLUK (TOLERANS)*}

"Hürriyet ihtimal ki zorla tesis olunur; Fakat herkese karşı, taassupsuzluk göstermekle ve aldırmamazlıkla muhafaza edilir."...

“Türkiye Cumhuriyeti'nde, herkes Allah'a istediği gibi ibadet eder. Hiç kimse dini fikirlerinden dolayı birşey yapılmaz. Türk Cumhuriyeti'nin resmi dini yoktur. Türkiye'de bir kimsenin fikirlerini zorla başkalarına kabul ettirmeye kalkısacak kimse yoktur ve buna müsaade edilmez. Artık samimi dindarlar, derin iman sahipleri hürriyetin gereklerini öğrenmiş görünüyorlar. Bütün bunlarla beraber, din hürriyetine, genellikle vicdan hürriyetine karşı taassup kökünden kurumus mudur?

* Bu bölüm, Medeni Bilgiler'in M.Kemal ATATÜRK'ün El Yazıları kısmından alınmıştır S.507-515 
Bunu anlayabilmek için, taassupsuzluğun ne olduğnu inceleyelim. Cü̈kü, bu kelimenin ifade ettiği manayı zihniyeti, herkes kendine göre anlamaya çok yatkındır. Dini hürriyeti bir hak olarak görmeyen, acaba kalmadı mi?

Vicdan hürriyetini, insan ruhunun, Allahın yüce hüküm ve nüfuzu altında, dini hayatı idare için, sahip olduğu haktan ibaret olduğunu bellemiş olanlar acaba bugün nasil düşünmektedirler? Bu gibiler, kendileri gibi düsünmeyenlere içlerinden olsun kızmıyorlar mı?

Bu saydı̆̆ımız zihniyete sahip olduğu düşünülen kimselere, hür düşünürlerimiz, acaba bir acı hisle, bir üzüntü ile bakmıyorlar mı?

Bu saydığımız gibi, çeşitli inanışlı kimseler, birbirlerine kin, nefret besliyorlarsa, birbirlerini hor görüyorlarsa ve hatta sadece birbirlerine actyorlarsa, bu gibi kimselerde taassupsuzluk yoktur, bunlar mutaassiptırlar (Bağnazdırlar). Vatandaşının veya herhangi bir insanın vicdanı inanıslarına karşı, hiçbir kin duymayan, aksine saygı gösteren kimsede taassupsuzluk vardır. Hiç olmazsa, baskalarının, kendininkine uymayan inanışlarını bilmemezlikten, duymamazlıktan gelir. Taassupsuzluk budur.

Fakat, gerçeği söylemek gerekirse diyebiliriz ki, hürriyeti, hürriyet için sevenler, taassupsuzluk kilimesinin ne demek olduğunu anlayanlar, bütün dünyada çok azdır. Her yerde, genel olarak geçerli olan, taassuptur. Her yerde görülebilen barıs manzarasının temeli, taassup ile hür fikrin birbirine karşı kin ve nefreti üstündedir; temelin devrilmemesi, kin ve nefret tabanındaki dengeyi tutan fazla kuvvet sayesindedir.

Bu söyleddiklerimizden şu sonuç çkar ki, aramızda, hürriyet engellerinin yok olduğuna, bizim gibi düşünün ve hissedenlerle birlikte yaşadığtmız yargısna varmak zordur. O halde, görülen, taassupsuzluk değil, zayıflığın güçsüz biraktı̆̆ı taassuptur.

Süphesiz fikirlerin, inanısların başka başka olmasından, şikayet etmemek lazımdır. Çünkü, bütün fikirler ve inanşılar, bir noktada birleştiği takdirde, bu hareketsizlik belirtisidir. Ölüm işaretidir. Böyle bir hal, elbette arzu edilmez. Bunun içindir ki, gerçek hürriyetçiler, taassupsuzluğun genel bir nitelik olmasinı arzu ederler. Fakat, hatta, iyiniyetle bile olsa, taassup hatalarına karşı, dikkatli olmaktan vazgeçemiyorlar. Çünkü iyi niyetler, hiçbir zaman, hiçbir şeyi tamir edememişlerdir. Insanların, ruhun selameti için yakildıklarını biliyoruz. Herhalde bunu yapan engisizyon papazlar, iyi niyetlerinden ve iyi is yaptıklarından bahsederlerdi; belki de, cidden bu sözlerinde samimi idiler. Fakat, bir ahmaklağın, yahut bir hainliği iyi bir kılıfa uydurmak güç değildir; en nihayet bu, bir isim değiştirmek meselesidir. İște, bu nedenledir ki, hosgurüyü aldırmamazlık, kayıtsızlık derecesine kadar götürmemek önemlidir. Gerçi, hür 
olmak herkesin hakkıdır ve bunun için gerçek hürriyetçiler, hürriyetçi olmayanlara karşı da genis davranılmasinı isterler. Fakat, bunların hiçbir zaman elleri ayakları bağlı olduğu halde kurbanlık koyun durumuna razı olacakları asla kabul edilmemelidir.

Unutulmamalıdır ki, bazı insanlar gelece ği, geçmişin arasindan görmekte ısrarlıdırlar. Bunlar, ilgimizi kestiğimiz geleneklere karşı mutlaka, bağlılı̆̆ın iadesini isterler. Bu gibi insanlar, kendi inandıkları gibi inanmayan kimseleri istedikleri gibi ezemezlerse, kendilerini cenderede (sıkısmış gibi) hissederler.

Herhalde taassupsuzluğun arzu edildiği gibi genelleşmesi, huy haline gelmesi, fikri terbiyenin yüksek olmasına bağlıdır."

Atatürk burada hoşgörüyü, hoşgörüsüzlüğü ve bunun tehlikelerini ve hoşgörünün sınırı konusunu da veciz olarak belirtmektedir,

Şimdi biz bu sınırı biraz açalım.

\section{HOSGÖRÜNÜN SINIRI}

Hoşgörünün anlamı ve içeriğinden herkesin her istediğini, her zaman, her yerde yapabilmesine müsaade etmek gibi bir anlam çıkabilir. Tabi ki bu mümküin değildir. Çünkü hoşgörü hürriyet kavramı ile iç içedir. Kişilere hakları olan hürriyetini kullanma imkanı veren bir kavramdır. Hürriyet ise hiç bir kişi için sınırsız değildir. Sınırsız hürriyet başkalarının hürriyetsizliği demektir. Toplum yaşantısında ise bu mümkün değildir. Kişi hürriyetine sınır, başkalarının hürriyet sınırıdır. Bu sınır aşılırsa hürriyetsizlik başlar. $\mathrm{Bu}$ nedenle insan hakları evrensel beyannamesine, hürriyeti yok edici hürriyetin tanınamayacağı maddesi konmuștur. Ayrıca toplumun, milletin ortak çıkarları ile devletin korunması hususları da, kişi hürriyetine sınır getirir.

Atatürk bu hususu 1931 yılında şöyle açıklamıştır.

"Kişilerin hürriyeti, devletin hakimiyet ve idaresinin korunmasina bağlıdır. Devlet idaresi felç olursa kişilerin hürriyetini koruyacak hiçbir kuvvet ve vasita kalmaz. Bu sebeple hürriyeti yalnız bir taraflı değil, her iki taraflı düşünmek gerekir.

Kişi hürriyeti kutsaldır. Bunların korunması için devamlı çalışılır. Fakat bu çalı̧̧mada devletin kuvveti, otoritesi hiçe sayllırsa, belki hiçe indirilebileceği dahi sanilır-ancak bu takdirde bu gibi insanların snunda kesinlikle başka bir devletin otoritesi altına girmek aşağllığına düşeceklerini, yabancı bir devletin hakimiyetinin esaret zincirlerini, kendi elleriyle, boyunlarına takmağa mecbur olacaklarını hatırdan çıkarmamak gerekir." 
Atatürk'ün ifade ettiği bu tehlikelerden dolayı, Anayasamız da, temel hak ve hürriyetlerini bazı durumlarda sınırlamış ve kötüye kullanılmasını önleyici hükümler koymuştur. Yani hoşgörüye sınır getirmiştir.

Anayasanın 14 ncü maddesi şöyle der:

"Anayasada yer alan hak ve hürriyetlerden hiçbiri, devletin ülkesi ve milletiyle bölünmez bütünlüğünü bozmak, Türk Devleti'nin ve Cumhuriyeti'nin varlığını tehlikeye düşürmek, temel hak ve hürriyetlerini yok etmek, devletin bir kiși veya zümre tarafindan yönetilmesine veya sosyal bir sinıfin diğer sosyal sinıflar üzerinde egemenliğini saglamak veya dil, ırk, din ve mezhep ayrimı yaratmak veya sair herhangi bir yoldan bu kavram ve görüslere dayanan bir devlet düzenini kurmak umaclyla kullanılamaz."

Bu açaklamalardan hareketle hoşgörünün sının konusunda şöyle bir senteze varabaliriz.

Hürriyet ve hoşgörü kavramlan içiçe olduğuna göre; hürriyetin olmadığı yerde hoşgörüden, hoşgörünün olmadığı yerde hürriyetten bahsedilemeyeceği için; hoşgörünün sınırı hürriyetin sınırıdır. Yani hürriyetin bittiği yerde hoşgörü de biter. Bu sınırı en açık şekilde Anayasanın 14 ncü maddesi ifade etmektedir. Bu maddenin kapsamina giren hususlarda bazı kimselerin kişisel hak ve hürriyetlerimi kullaniyorum düşüncesiyle faaliyette bulunmaları Anayasa'ya göre suçtur; Bunlara göz yummak da hoşgörü değil yine anayasal suçtur. Bu maddenin içeriğini özetlersek, hiçbir kişinin bütünlüğümüzü bölmeye, devleti ve cumhuriyeti tehlikeye düşürmeye, hak ve hürriyetleri yok etmeye, eğemenliğin kaynağını değiştirmeye, bölücülük ve ayrıcılık yapmaya, farklı bir devlet düzeni, yani dine dayanan, rrka dayanan, demokratik, laik ve sosyal hukuk devleti anlayıșı dışında bir anlayışa dayanan devlet düzeni kurmaya yönelik hakkı ve hürriyeti yoktur. Dolayısıyla hoşgörü devlet, millet ve kişi seviyesinde de burada biter; Burada hoşgörü yerine kişinin, toplumun tepkisi, devletin kanunlanı çalışmaya başlar.

Atatürk'ün dediği gibi "Hoş görmekliği aldırmamazlık derecesine götürmemek önemlidir." Bu nedenle hoşgörü sınırlarını aşanlara karşı aldirmamazlık; yurdunu ve milletini seven, kendisinin ve toplumun ortak çıkarlarını görebilen, vatandaşlık görevlerinin bilincinde olan kişilerin davranışı değildir.

Çünkü hoşgörü, kayıtsızlık ve adam sendecilik değildir.

\section{HOSGÖRÜSÜZLÜK-TAASSUP}

Hoşgörünün karşıtı hoşgörüsüzlük, taassup, bağnazlıktır. Hoşgörüsü olmayan kişi de mutaassıptır, bağnazdır, hoşgörüsüzdür. 
Atatürk, Medeni Bilgiler'de mutaassıbı şöyle açıklar:

"Muhtelif inançl kimseler, birbirlerine, kin nefret besliyorsa, birbirlerini hor görüyorlarsa ve hatta sadece birbirlerine actyorlarsa, bu gibi kimselerde taassupsuzluk (hosgörü) yoktur, bunlar mutaassiptırlar."

Taassubun sebepleri ise:

a. Cehalettir,

b. Menfaattir,

c. Alışkanlıktır,

d. Korkudur.

Toplumumuzda hoşgörüsüz kişiler incelendiğinde görülür ki onlar ya cahildir, ya başka fikir sahiplerine hoşgörü ile davranmak çıkarlarına aykındır veya alıştıkları şeyden vazgeçmek onlara güç gelmektedir yahut şuuraltı, şuur üstü bir korkunun tesiri altındadırlar.

Hatta hoşgörüsüzlüklerin şiddeti de bu korkunun derecesine bağlıdır.

Dünyanın dönmediğini iddia eden papazlara, döndüğünü söylemekten çekinmeyen Galile, hem cehaletin, hem de korkunn sebep olduğu bir taassup yüzünden zindana atılmş ve öldürülmüştür. Bu olayda papaz zümresinin menfaatlerinden doğan bir taassup da görülmektedir. Çünkü Avrupa'daki reform hareketlerinden sonra menfaatçci papaz zümresi ortadan kalkmak zorunda kalmıştır.

Taasubun en ağırlıklı sebebi cehalettir. Atatürk, 1923 yılında İstanbul gazetecileri ile Izmit'te görüşürken taassup hastalığın cehalete bağlar, ilaç olarak da ilmi tavsiye eder ve şöyle der:

"Taassup cahilliğe dayanır. Bundan dolayı taassubu olan cahildir. İlim mutlaka cahilliği yener. O halde halkı aydınlatmak lazımdır.”*

Buradaki cahilin kim olduğunu, ilmin ne olduğunu anlamak için Atatürk'ün 1923 'te Tarsus'ta çiftçilerle yaptı̆̆ konuşmanın bir cümlesine bakalım:

"Biz cahil dediğimiz vakit mutlaka mektepte okumamıs olanları kastetmiyoruz. Kastettiğimiz, ilim hakikati bilmektir. Yoksa okumus olanlardan en büyük cahiller çıktığı gibi hiç okumak bilmeyenlerden de bilhassa sizlerin içinizde görüldü̈̆̈̈ gibi, hakikati gören hakiki alimler çıkar.”**

* Gazi Mustafa Kemal Atatürk'ün 1923 Eskişehir-İzmit Konuşmaları, Hz. Arı İnan, T.T.K.Ankara-1982, s.73

** Atatürk'ün Söylev ve Demeçleri, C.11, 3 ncü baskı, Ankara-1981, s.132 
Demek ki taasssubu önlemenin çaresi ilimdir, yani gerçeği, doğruyu öğrenmek ve öğretmektir.

Burada kişilere düşen görev aydın olmaktır. Yani düşüncesini inancından; ilimi, bilimi dinden ayrn tutmaktir.

Her türlü fikre açık olmak, önyargısız dinleyebilmek, tartışabilmek; her duruma ve fikre, çağdaş insanın düşünme temelini oluşturan acaba, neden, niçin, nasıl sorulan ile yaklaşabilmek ve şüpheci olmaktır.

Ayrıca kendi gerçeklerinin tek ve en doğru olmayabilceğini; kendi dünyasının dışında başka dünyaların olabileceğini; bu nedenle de herkes için geçerli olan bir tek dünya, bir tek doğru, bir tek gerçek olmadığını kabul etmelidir.

Aksi takdirde toplumun huzuru ve düzeni, iç barıs, birlikte yaşama istek ve arzusu ortadan kalkar. Ayrılıklar gruplaşmalar başlar, milli birlik ve beraberlik duyguları zedelenir. Son aşamasında ise devletin ülkesi ve milletiyle bölünmez bütünlügü tehdit altına girer.

Herkesin tek sesli bir toplum olamayacağını, tek sesliliğin faydadan ziyade zarar getireceğini çok sesliliğin bir doğa kanunu olduğunu kabullenmesi gerekir. Tek esli toplumlar gelişemezler, ilerleyemezler, Atatürk bunu şöyle açıklar:

"Fikirlerin, itikatlerin başka başka olmasindan, şikayet etmemek lazımdır. Çünkü, bütün fikirler ve itikatler, bir noktada birleștiği takdirde, bu hareketsizlik alametidir. Öyle bir hal elbette arzu edilmez."**

Çünkü hareketsizlik durma, durma ise gerilemedir. Gerilemek istemeyen toplumlar çok sesli olmak zorundadır. Çok seslilik ise taassubun ortadan kaldırılmasıyla mümkündür.

Taassup toplumu geriletmekle beraber, gerçeklerin, doğruların ortaya çıkmasını da önler. Taassup; fikrin doğmasını; fikir alışverişini, kişilerin düşüncelerini istedikleri gibi söyleyebilmelerine engel olur. Atatürk'ün dediği gibi:

"En büyük hakikatler ve terakkiler fikirlerin serbest ortaya konması ve teati edilmesi ile meydana çıkar ve yükselir."**

O halde ilerliyebilmek için taassubu mutlaka ortadan kaldırmak gerekir. Mutaassıp bireylerden oluşan toplumlar gerilemeye mahkumdurlar.

* Medeni Bilgiler, s.57

** Medeni Bilgiler, s.58 
Taassup insanın doğasına aykırıdır. İnsan, düşünebilme, düşünce üretme, maddi birşeyler yapabilme yetenekleri ile donatılarak yaratılmıştır. Toplumların ilerlemesi de insanın bu yeteneğinden kaynaklanır. Taassup bu yeteneğin kullanılmasını frenler, zamanla söndürür. İnsanın doğasına saygı duyanın taassubu olamaz. Tassup, insanın yaratılış özelliklerine terstir, yaratanın insanı yaratma felsefesini inkardır.

Taassup fikir ve hiürriyetini söndürür. Her nekadar yasalarda yer alsa dahi; taassup statikliği, dogmaları ön plana çıkardığından, ilkleri, yenileri hoşgörmediğinden; Fikir hürriyeti kağıt üzerinde kalır. Taassup ortamında fikirler korkusuzca ve serbestçe ifade edilemez.

Fikirlerin korkusuzca ve serbestçe ifade edilmesi, aslında fikir hürriyetinin son merhalesidir. Asıl fikir hürriyeti, fikirlerin doğru doğması yani doğru düşünebilme yeteneğidr. Yani beyin içinin hürriyetidir. Beyin içinin serbest olması, dogmalarla, kalıplarla doldurulmamış ve dondurulmamış olmasıdır. Bu da hoşgörü ile sağlanır. Hoşgörüsüzlük, davranışlardan önce beyin içinde çekingenlik ve zamanla tembellik yaratır. Çalışmayan bir beyinden ve sahibinden de hiçbir şey olmaz, hiç bir verim alınamaz. O nedenle fikri hoşgörüyü sadece dilin veya kalemin değil, beyin içinin serbest olması diye kabul etmek gerekir.

Beyin içi; hurafelerle, batıl itikatlarla, muhakemesiz, tartışmasız kabulü şarttır şeklindeki bilgilerle; tersini veya zararını, doğruluğunu, yanlışlığını düşündüğünde, manevi baskı altında kalınmasını sağlayacak hususlarla doldurulduğunda, fikri hoşgörü ortadan kalkar. Beyin içi serbestisini kaybeder.

Atatürkçülüğün öngördüğü fikri hoşgörü, herşeyin doğrusuna, eğrisine, iyisine, kötüsüne, faydasına, zararına kişinin kendisinin karar vermesidir. Hertürlü baskıdan uzak olarak serbestçe düşünebilmesidir. Yani fikri hür, vicdanı hür, irfanı hür olmasıdır.

\section{NUÇLAR \\ HOŞGÖRÜSÜZLÜĞÜN (TAASSUBUN) DOĞURACAĞI SO-}

Taassup gelişmenin ilerlemenin düşmanıdır. Diyebiliriz ki Osmanlı Devleti'nin yıkılmasına sebep batıya, ayak uyduramamasından, ayak uyduramaması da din düşmanlığından, dini bağnazlıktan kaynaklanan taassuptur. Ayrıca kişilere hoşgörünün gereği olan serbestilerinin verilmemesidir.

Çarpıcı birkaç örnekle bu düşüncemizi kuvvetlendirelim.

- Dini Taassup yüzünden matbaa 277 yıl sonra kullanılmaya başland. Bu bile başlı başına bir olaydır. Yaygın cehalet 300 yıl daha devam etti demektir. 
- 1575'de kurulan İstanbul Rasathanesi, 1580 'de "rasat yapmanın, evrenin sırlarını öğrenmeye yönelik bir küstahlık olduğu ve rasathane kuran deletlerin mahkum olacağı" düșüncesiyle yıktırıldı.

- Hür düşünceye, akla ve bilime dayalı gerçekçi düşünmeye yer verilmemesi, bunun yerine sanki dinin gereğiymiş gibi bazı safsatalarla karar verilmesi sonucu çok şey kaybedilmiş, başta harpler kaybedilmiştir. 1839 'da Mısır Valisi Mehmet Ali Paşa'nın ordusuna Nizip Muharebesi'nde yenilmenin sebebi bundandır. Din adamları cuma günü savaşılmaz, bu dini aykarıdır deyince, askeri yönden durum Osmanlı Ordusu lehine iken taarruz edilmedi. Daha sonra, bir gece baskını için daha müsait bir durum doğdu. Din uleması buna da karşı çıkarak, haydutlar gibi baskın yapmanın padişah askerine yakışmayacağını söylediler.

Yakın tarihten bu anlayışa bir örnek daha verelim. Balkan Harbi'nde Makedonya'da yenilen ordumuz Arnavutluk'a doğru çekilir. Bu arada bir büyük grup istikametini kaybeder, hangi yöne çekilmeye devam edeceğini şaşırır. Komutanlar toplanır, karar vermek için Kuran'ı Kerim açarlar.

- Tanzimat'tan sonra yeni açılan orta okullarda harita ile coğrafya dersi okutulmaya başlanır ancak bu "coğrafya derslerinde harita göstermenin kafir adeti olduğu ve şeriatın buna cevaz vermediği" fetvası ile kaldırılır. Oysa Piri Reis, dünyaca ünlü haritasını 1513 'te, yani 3,5 asır önce çizmişti.

- 19 ncu yüzyılda camilere paratöner taktırılamamıştır.

- 19 ncu yüzyılın ikinci yarısında batının kullandığı çiçek aşısı yerine merkep sütü içirilmesine cevaz verilmiştir.

- Tibbiyedeki anatomi derslerinde müslüman cesetlerinden yararlanmaya izin verilmemiştir.

Bu örnekleri çoğaltmak mümkündür. Bu örneklerden şunu çıkarıyoruz, dini taassup endişe edilecek bir durumdur. Türk tarihinde dini taassup çağdaşlaşmak için girişilen yeniliklerin karşısında güçlü bir engel oluşturabilmiştir. Türkiye'nin çağdaşlaşmada geri kalma sebebi taassuptur.

Bugüne baktığımızda 1993'te Sivas'ta 37 kişinin yanarak ölümüne sebep, taassuptur. 1980 öncesi K.Maraş ve Sivas olaylarının sebebi yine taassuptur. Bugün kendisini dini bütün görenlerin, dini yönden kendisi gibi olmayanlara karşı tavrının sebebi yine taassuptur. Bunların başka 
dinden, mezhepten olanlara duyduklan kinin, düşmanlığın sebebi tassuptur.

Taassup, hoşgörüsüzlük, düşmanlık doğurur, milleti gruplara, zümrelere ayırır, kavgaya, iç çatışmaya sebep olur, sonu bölünmelere kadar gider. Onemli bir tehlikedir.

\section{SONUÇ}

Bu tehlikenin daha da büyümemesi, dini taassubun arkasından ırki taassubun gelmemesi için her Türk vatandaşı taassubun sonucu üzerine bilinçli olmalıdır. Sonucu görebilmelidir. maktır.

Bilincin doğmasının anahtarı yasalara uymak, gıdası da şüpheci oltir.

Hoşgörünün dershanesi kütüphanelerdir, kitaplardır, hocası da tarih-

Eğer Cumhuriyeti korumak istiyorsak, eğer laik düzende yaşamaya devam etmek istiyorsak, eğer demokrasinin nimetlerinden yararlanarak insan gibi yaşamak istiyorsak, eğer herkesin yasalar önünde eşitliğini ve herkesin eşit haklara sahipliğini öngören çağdaş hukuk düzeni içerisinde yaşamak istiyorsak, eğer bize miras bıkarılan ata yadigarı güzel vatanımı$\mathrm{z}$ böldürmek istemiyorsak, eğer yurtta ve dünyada barış içinde yaşamak istiyorsak, eğer refah düzeyimizi daha da artırmak istiyorsak hoşgörülü olmalıyız ve hoşgörüsüzleri de hoşgörülü yapmanın yollarını bulmalıyız. Hoşgörüsüzleri hoşgörü ile karşılamamalıyız. 